\title{
JUSTICE AND EQUAL OPPORTUNITIES IN HEALTH CARE
}

\section{JOHN HARRIS*}

\section{ABSTRACT}

The principle that each individual is entitled to an equal opportunity to benefit from any public health care system, and that this entitlement is proportionate neither to the size of their chance of benefitting, nor to the quality of the benefit, nor to the length of lifetime remaining in which that benefit may be enjoyed, runs counter to most current thinking about the allocation of resources for health care. It is my contention that any system of prioritisation of the resources available for healthcare or of rationing such resources must be governed by this principle.

This can have apparently paradoxical conclusions in that it can seem wasteful to give someone with a very slim chance of a lifesaving treatment the same priority as someone with a much better chance. In an important and thoughtful recent paper, Julian Savulescu has concentrated on this apparent weakness and has argued for a particular conception of the good or benefit to be achieved by a healthcare system which purports to demonstrate the inadequacies of an equal opportunities approach to prioritisation and to replace it with an altogether better account. This paper will show that a rational 'reasons based consequentialism' is more in line with the equal opportunities approach, which I defended some time ago in these pages, than with that of Savulescu. I shall then examine more closely the conception of equal opportunities in health care and show that if we give weight to an individual's reasons, and what is expected to be good for them, we will opt for exactly the equality based account of distributive justice that I have recommended.

The principle that each individual is entitled to an equal opportunity to benefit from any public health care system, and that this entitlement is proportionate neither to the size of their

* Thanks are due to two anonymous referees for Bioethics. 
chance of benefitting, nor to the quality of the benefit, nor to the length of lifetime remaining in which that benefit may be enjoyed, runs counter to most current thinking about the allocation of resources for health care. It is my contention that any system of prioritisation of the resources available for healthcare or for rationing such resources must be governed by this principle.

This principle can lead to apparently paradoxical conclusions in that, for example, it can seem wasteful to give someone with a very slim chance of a lifesaving treatment the same priority as someone with a much better chance. I set out the above ideas in this journal some time ago, ${ }^{1}$ and in an important and thoughtful recent paper, ${ }^{2}$ Julian Savulescu has concentrated on this apparent weakness and has argued for a particular conception of the good or benefit to be achieved by a healthcare system which purports to demonstrate the inadequacies of my approach and to replace it with an altogether better account.

Savulescu identifies my theory of the good of healthcare as providing each individual with an opportunity to live the best and longest life possible for him or her, and dubs this theory 'opportunism'. Savulescu notes that for the purposes of distribution of resources, I reject welfarism (the thesis that the good of health care is well-being) and that I have argued that utilitarianism in general may lead to de facto discrimination against groups of people needing health care. It is true that I do reject the thesis that the good of healthcare is well-being, but if welfare is defined in terms of preference satisfaction as it very often is, then what I have to say about equal opportunities in health may well be compatible with welfarism thus conceived. ${ }^{3}$

Savulescu argues that well-being is a superior theory of the good of health care to mine and that the weaknesses of utilitarian approaches that I have identified can be better addressed in two ways, by: (1) relating justice more closely to reasons for action and (2) by conceptualising the relationship between reasons for action and the value of the consequences of those actions as a

1 John Harris 'What Is the Good of Health Care?' Bioethics 10:4 1996 269291. Justine Burley and Søren Holm have made helpful comments on an earlier draft of this paper. The author thanks the European Commission (DG XII) for a project grant, which made this work possible.

2 Julian Savulescu, 'Consequentialism, Reasons, Value and Justice' Bioethics 12:3. 1998. 212-235.

3 See for example Amartya Sen, 'Well-Being, Agency and Freedom', Journal of Philosophy 82, 1985. 187ff. See also G.A. Cohen 'On the Currency of Egalitarian Justice', Ethics 99. 1989 pp. 906-909. 
plateau rather than as a scalar relationship. Justice, Savulescu suggests, can be understood as satisfying as many equally rational claims on resources as possible and that the rationality of a person's claim on health resources turns on the strength of that person's reasons to promote certain health-related states of affairs.

Savulescu's point is that 'the strength of that reason does not track the expected value of that state of affairs in a fully scalar fashion. Rather a person can have most reason to promote some state of affairs, even though he or she could promote other more valuable states of affairs. Thus there can be equal reason for a distributor of public resources to save either of two people, even though one will have a better and more valuable life.' Savulescu's claim is that this 'approach, while addressing many of Harris's concerns about utilitarianism, does not imply that doctors should give up prioritising patients according to prognosis altogether, but it does imply that patients with lower, but reasonable prognosis should share in public resources'.

The concentration on a reasons based solution to problems of allocation has many attractions and is worth pursuing. I shall first show that a rational 'reasons based consequentialism' is more in line with my 'equal opportunities for health' than with Savalescu's position. I shall then examine more closely the conception of equal opportunities in health care that is at issue between us and show that if we give weight to an individual's reasons, and to what is expected to be good for them, ${ }^{4}$ we will opt for exactly the equality based account of distributive justice that I have recommended.

\section{REASONS BASED CONSEQUENTIALISM}

\section{What does a rational person have good reasons to promote?}

If we ask what state of affairs I (or anyone) has most reason to promote, an obvious answer would be our own survival. ${ }^{5}$ It surely must always be rational for someone who wants to live to choose a chance of continued survival over earlier death, even where the survival period will be relatively short or where the chances of survival are slim, so long as the life to be continued will likely be of acceptable quality. The strength of the agent's reason will be relative to the desire to live or to the fear of death, not to the

4 Savulescu 1998 p. 235.

${ }^{5}$ We'll ignore cases in which our survival is incompatible with that of someone we care deeply about. 
chances of survival. If the chances of my survival are slim, I may be irrational to believe that I will in fact survive, but I surely am not irrational to take any chance of survival that offers, unless other costs to me (or to things I ought to value more, or would be irrational not to value more,) are greater. And here, of course, the strength of the desire to take a chance on life need not be proportional to the chances of that desire being realised.

We should note that while pursuing goals with scant chance of success is often an irrational activity, it is so because there are better (more rational) uses of one's time. So it would be irrational for a person to pursue a course of professional training if there were very little prospect of gaining anything useful from it. But if it is irrational, it is so because there are better (more likely successful) uses of that person's time, the course is literally time wasted. But where what is pursued is continued existence, which is the sine qua non of the pursuit of almost all other goals, it can hardly be irrational or unreasonable to pursue life however slim the chance. There are no more rational uses of that person's time for that person is pursuing time itself, ${ }^{6}$ nor are there more rational goals he might pursue, for what he is pursuing is the condition of almost all other objectives he may have. A slim chance of something $^{7}$ is always better (more objectively rational) than a certainty of nothingness.

\section{Reasons and Justice}

Savulescu sets out a plausible account of reasons-based justice and applies it to health related claims. Savulescu outlines his position as follows, and I will quote in sufficient detail to make the subtlety of his argument clear:

Justice is concerned with providing what there is good reason to provide for people. Let's say that a person has a rational claim to have some state of affairs, $p$, promoted if there is good reason to promote p. According to one version of consequentialism,

C1. The good of health care is satisfying a rational claim for some health-related state.

C2. The right distribution is that distribution which maximises the number of people whose equally rational health-related claims are fully satisfied.

${ }^{6}$ With apologies to St. Augustine!

7 If desired. 
Call this view reasons-based maximising consequentialism for short. According to reasons based consequentialism the following claims are true:

C3. If a person (including a distributor of public resources) has equal reason to promote $\mathrm{p}, \mathrm{q}$ or $\mathrm{r}$, and that person can promote either $\mathrm{p}$ and $\mathrm{q}$, or $\mathrm{r}$, then he or she should promote $\mathrm{p}$ and $\mathrm{q}$.

C4. If a person, $A$, has the same strength reason to promote $p$ as another person, $\mathrm{B}$, has to promote $\mathrm{q}$, there is as much reason to promote $\mathrm{p}$ as $\mathrm{q}$. Thus, the distributor can have as much reason to provide $A$ with the resources so that $p$ is promoted as she can to provide resources to B to promote $q$. To use the preceding example...

A distributor of public resources can have the same strength reason to promote $\mathrm{A}$ in $\mathrm{p}$ (if that is what $\mathrm{A}$ most cares about) as to promote $\mathrm{B}$ in $\mathrm{q}$ (if that is what B most cares about), even if $q$ is more valuable than $p$.

There are limits to this principle. When the expected value of one option greatly outweighs the expected value of another option, we are rationally required to choose the former ... Consider ... a related but slightly different example. Two 70 year old men have cancer and will die without treatment.

[Each loves his family dearly, the treatment is expensive and will leave each with little to bequeath]

Man A has a 1/50 chance of survival.

Man B has a 1/100 chance of survival.

$[\mathrm{M}] \mathrm{y}$ intuition about this case is that there is as much reason for each man to choose a chance on life rather than his family's welfare...

Compare these men to Man C. He has the same disease, the same assets and the same concern for his family. However, he has a 1/1000000 chance of survival. If Man C cares greatly about his family's welfare, he should not spend his money on the experimental treatment. The expected value of the operation is so small that the strength of his reason to have the operation is weaker... ${ }^{9}$

8 This is an astonishing claim for someone sporting utilitarian credentials because any gain in utility is a gain in utility!

9 Ibid. p. 232. 
Savulescu says of man C who has only 1/1000000 chance of survival: 'The expected value of the operation is so small that the strength of his reason to have the operation is weaker'. But this is neither true nor plausible unless stipulated so to be. The value of the operation is as great as it could conceivably be, it is a life saving operation, it is C's only chance of continued life, just as for $\mathrm{A}$ and $\mathrm{B}$ who have a $1 / 50$ and $1 / 100$ chance respectively. On the view of what each stands to gain the value is equal, it is the value of a chance of survival versus the value of no chance of survival. True, $\mathrm{C}$ will not be rational if he believes that he has a good chance of survival, but then neither will A or B. True, also, C has a much worse chance of survival than A or B. I have suggested that in cases like this the value of the operation to $\mathrm{A}, \mathrm{B}$ or $\mathrm{C}$ is the value of a chance of survival. The moral reason to afford any of them that chance is simply that equality demands it. The requirement that each person is shown the same concern, respect and protection as is shown to any, requires that the life of each person be equally respected. In this sort of case, I have suggested, this means giving to each his or her chance, ${ }^{10}$ whatever that chance may be. ${ }^{91}$

Perhaps Savulescu has a false analogy in mind here. If I am faced with a choice between rival therapies for the same condition, and one has a much greater chance of success than the other, I have a stronger reason to prefer the therapy that offers the best chance. But this case tells us nothing about 'stronger reasons' when we are comparing not a slim chance with a fat chance, but a slim chance with no chance at all; or when the slim and the fat chances fall to different people.

Savulescu, like many before him, is playing fast and loose with the meaning of the crucial phrase 'expected value'. He started by using the term 'expected value' to refer to the magnitude or importance of the benefit to be achieved by treatment, not to the likelihood of the benefit being realised. I agree with Savulescu when 'expected value' refers to magnitude and importance of the benefit. I have always maintained, as Savulescu concedes, that for example, life saving procedures are usually to be preferred to life enhancing procedures, precisely because of the magnitude of

${ }^{10}$ If that chance is wanted or claimed.

11 Remember, although it may be hard to calculate, each claimant on health resources has, in fact, a different chance of benefit so any requirement to give all an equal chance cannot coherently refer to size of benefit or to the magnitude of the chance of obtaining that benefit unless equal just means 'proportional to size of benefit'. 
the benefit. ${ }^{12}$ And I also agree with him that except where differences in magnitude are clear and sizeable it is better to respect a person's own preferences. Thus a distributor of public resources can have the same strength reason to promote what $\mathrm{A}$ most cares about as to promote what B most cares about, even if one is more valuable than the other.

I have argued that the value of someone's life either cannot, or should not, be proportional to their life expectancy, nor to their chances of achieving that expectancy. ${ }^{13}$ There are many reasons for this and here I will mention two. Genome analysis will soon be able to reveal, at conception or birth, many reliable differences between individuals with respect to their life expectancy and their chances of continued existence when genetically predicted illnesses take hold. It would surely be invidious to distinguish between individuals on this basis, not least because it would amount to renunciation of the equality principle. If equality of consideration varies with life expectancy or chances of successful treatment and these are for everyone unique, then the value of each life is different, not equal.

Savulescu partly accepts this but believes that really slim chances change the game, a 1/1000000 compared with a $1 / 100$ chance for example. There is some plausibility to this, but there are a number of problems too. First, I doubt there would be any consensus about how small a chance carries with it loss of equality of status. ${ }^{14}$ Many would think $1 / 100$ chance is far too small. What rational person would play 'Russian Roulette' where the chance is $1 / 6$ ? The answer of course is it depends what is at stake. No rational person would play for a $1 / 6$ chance of death, but when it is the only chance of life why not take even a $1 / 1000000$ chance? It can't be irrational to take such a chance, although it may be selfish when costs to others are included in the calculation. In

12 Savulescu, like several of my other critics, seems unable to distinguish between situations where life is at stake and situations where a person will survive with better or worse quality of life. In the former case it is always rational to take a very small chance on life, in the latter it may be rational to discount the value of the various outcomes with the probability of achieving them.

13 See for example my 'More \& Better Justice' in Sue Mendus and Martin Bell Eds. Philosophy And Medical Welfare, Cambridge, University Press, 1988. 7597. 'QALYfying the value of life' in The Journal of Medical Ethics Vol.13 No 3. September 1987. p. 118. 'Could we hold people responsible for their own adverse health?' in The Journal of Contemporary Health Law and Policy Vol. 11996. 100-106. 'What the principal objective of the NHS should really be' in The British Medical Journal 314. 1st March 1997. And my The Value of Life Routledge \& Kegan Paul 1985.

${ }^{14}$ For that's what it amounts to. 
such a case, the argument must be about enforcing 'altruism' or about the objectivity of the size of the benefits, that is about the superiority of a maximising consequentialism.

But reasons based maximising consequentialism, of the sort espoused by Savulescu, cannot help here because it implies that the rationality of reasons for doing $\mathrm{x}$ is proportionate to the likelihood of achieving $\mathrm{x}$; but this depends on what is at stake and what the alternatives are. When life is at stake and one alternative offers a chance of life (and there are no other alternatives which offer any chance of continued existence for the agent) then, arguably, any chance is worth having and therefore rational. This will be true unless the reasons the agent has to give others a chance of rescue are for some reason stronger than those she has to save her own life.

\section{EQUAL OPPORTUNITIES AND DISTRIBUTIVE JUSTICE}

Savulescu suggests that if I am saying 'something new and interesting, I think we should understand [Harris] literally as saying that the good of health care is opportunity not welfare, and that opportunities are to be distributed among people, as utilitarians distributed welfare'. ${ }^{15}$ He then identifies three ways in which opportunity as a good might be interpreted and finds fault with all of them. These are, crudely, that opportunity might be an intrinsic good, an instrumental good or what he calls a subjective intrinsic good. He points out, rightly, that each of the first two alternatives is flawed if strictly and exclusively interpreted. However, I am not claiming that equal opportunities for health care are either intrinsic or instrumental goods, they are both and more, like other accounts of the moral requirement for equal opportunities.

A denial of equal opportunities is a slap in the face; it is an existential rejection disproportionate to the value of the good or welfare that the opportunity might have afforded. So it is not the case that the opportunity is valuable only for what it is an opportunity to do or to be, nor is it merely valuable in itself. Equal opportunities recognise the existential or intrinsic value of people, they are neither simply intrinsic goods nor are they simply instrumental. Rather it is the case that the keeping open of opportunities is expressive of, and recognises that the person's objectives (whatever they are - however trivial or important) matter. When people champion equal opportunities in

15 Savulescu 1998, pp. 217-218. 
education, or to use public utilities (buses, for example, or lavatories) the liberty is not valuable in proportion to the importance of the particular object of the liberty (to make a journey by bus or wash your face). They are important because the denial of them is a rejection of equality and therefore an affront to human dignity.

\section{Counting and discounting}

Savulescu ${ }^{16}$ attributes to me the suggestion that 'life per se is not of value, but of value to the extent that a person values it.' I stand by this remark so far as it goes. Savulescu goes on to claim that 'this strategy will not justify Harris' intuitions in the medical example because, even if every patient's life has value of 1 , we must discount the value of operating on patients... by the probability that the operation will not achieve the valued outcome'. ${ }^{17}$ Savulescu believes that the 'implication of these claims is that each person values having the operation to the same degree. On this view, opportunity is good to the extent that it is valued. Thus, if Tom, who has a brain tumour, wants the opportunity to live just as Alex, who has appendicitis, this grounds an equal moral claim, regardless of how great their chances are.' And Savulescu interprets this position as amounting to 'holding a ticket in a lottery not because of the money we might win, but simply for the chance to participate in the lottery'. But this is surely wrong. Tom has more than a chance of participating, and he wants more; he has and wants a chance of winning, winning the thing that matters most to him, his continued existence.

Of course, the opportunity of the operation is valued because it is seen as a means to continued existence. Tom and Alex each want the same thing, a chance of continued existence; although for each the chance is different and for each continued existence will be different (different length, different quality etc.). This no more shows that what each wants must be discounted for its peculiar value than does the fact that each human being is different show that the value of life is different for each and hence that there can be no such thing as a principle of equality.

To assert 'even if every patient's life has a value of 1 , we must discount the value of operating on patients by the probability that the operation will not achieve the valued outcome' involves a

16 Ibid. p. 219.

17 Ibid. p. 220. 
fundamental fallacy. If every opportunity had to be discounted by the probability that it will achieve its objective there could be absolutely no claim to the equality of public provision of anything. Education is effective in proportion to the intelligence, ability to concentrate, application, capacity for hard work etc. of each and every student and these are different for each and every student. Access to education must be finely graded accordingly. The value of the provision of public lavatories is, on this view, proportionate to the strength of the bladder of individual users, in that the utility of the operation in question, how long before another, similar operation is required, is one obvious measure of the utility of restroom provision.

\section{The fallacy of the principle of temporal neutrality}

Savulescu also appeals to this principle of discounting when discussing the so called 'principle of temporal neutrality'. According to this principle if 'the value of a state of affairs is determined by our desires for that state, we should appeal not only to what people now desire, but also to what they will desire. And if we consider future preference satisfaction, we must discount the value of that satisfaction by the probability of it not occurring'. ${ }^{18}$ Imagine a nation state 'Temporal Neutralitovia' (TN) that has two potential and very powerful enemies. One declares all out war reducing the chances of survival of all TN's inhabitants by $50 \%$. The second enemy can now reason, correctly according to Savulescu, that if it also declares war the wrong it will do in waging war and probably killing many of TN's inhabitants is only half what it was previously, because the value of the lives of all the inhabitants of TN must be reduced by $50 \%$, must, in short, be discounted by the probability of their survival.

To move from the cataclysm of war to more mundane and realistic policy choices: we can imagine two towns of exactly the same size in the European Union, one in the north of England, 'Ancient', and the other in the south of Italy, 'Vecchio'. Both towns are claimants for Community resources available to care for the elderly. As is well known, life expectancy is greater in southern Italy than in northern Europe, perhaps due to the famous 'Mediterranean diet' of olive oil and cooked tomatoes. The citizens of both towns want the security of better health provision in old age. They want it now and will still want it when they are old. However, although both towns have equal size

${ }^{18}$ Ibid. p. 221. 
populations, since life expectancy in Vecchio is much superior to that in Ancient, we must discount the value of devoting resources to the elderly the probability that the allocation will not achieve the valued outcome. That is, fewer elderly will benefit in Ancient than in Vecchio. Is it clear that the citizens of Vecchio have the better claim, and that the European Commission, for example, should allocate resources accordingly? Should Italy and Greece always win out over the United Kingdom and Denmark when such resources are available? I doubt this would (or should) strike the European Parliament, for example, as an equitable allocation of resources between member states.

The fallacy of the principle of temporal neutrality lies in attempting to extrapolate from decisions within particular lives to comparisons between lives where life itself is at stake. If the claim that if we consider future preference satisfaction, we must discount the value of that satisfaction by the probability of it not occurring' has any validity this derives from its application within a particular life. I would be irrational to plan for future preferences I am unlikely to be able to satisfy. But this is entirely different, as the above examples show, to the false claim defended by Savulescu, that we must discount the existential value of a life by the probability of its not continuing.

In any event Savulescu has already conceded enough of the point. He allows that it is invidious to prefer a $1 / 50$ chance of life to a $1 / 100$ chance so it is clearly not true that in his view we must discount for probability of occurrence. However, if, as I have argued, the value lies in giving the person an equal chance of continued existence, and that doing so recognises their equal standing in the community, then that is the value of the opportunity. And we have already seen that the explanation of this exception cannot be simply a matter of the externally assessed rationality or of the strength of the agent's reasons for the choice.

\section{Thresholds and plateaux}

Savulescu's claim is not that it is simply a matter of the strength of the agent's reasons for choice, but of that strength once a certain threshold or plateau is reached. His suggestion is that 'the strength of reason to act increases as the value promoted by the action increases, until some plateau is reached where strength of reason no longer increases despite increments in value. Thus a person may have most reason to perform some act, even though other actions would promote more value, if the consequences of the 
chosen act are good enough'. ${ }^{19}$ Savulescu makes clear that 'Distributors of public resources should not require that agent's change what matters most to them, provided that the object of that pattern of concern is worth achieving and good enough relative to other alternatives' ${ }^{20}$ The crucial point is that Savulescu believes that a slim chance of life is not a reason on the plateau, not something either worth achieving or good enough relative to other values.

I have argued that a chance of continued existence that is desired is always worth taking and that it is only other values of the same agent that can eclipse that chance. The object of the chance of life is not, as Savulescu sometimes implies, the particular percentage chance, but the opportunity of life when the alternative is death. Thus the measure of the good to be achieved does not reside in the percentage chance of achieving it, but in the nature of what is to be achieved. Continued existence as opposed to immediate death is desired because it is everything as opposed to nothing. There could not be a more valuable objective or a more rational one. This must be on Savulescu's plateau if anything is.

What Savulescu must surely do is provide a principled account of when precisely differences in degree make for differences in quality, or in his terminology when scalarity breaks down. Without a principle for recognising the point of scalar shift, we have been given no account of anything, but merely a redescription of Savulescu's intuitions.

\section{The value of life}

The plateau or threshold is I concede attractive. Savulescu is certainly right to suggest that most people's intuitions suggest that really small chances of survival are not worth providing (as opposed to taking) when the same resources could be used to give better chances to others and hence save more lives. The same seems to be true where even good chances of continued life are available, but where the continuance will be only for very short periods, days or weeks for example. It may be that this is an objective matter in that a vast majority would see small chances or short periods of remission as obviously worthless or worth less. However, this paper has suggested that such plateaux are not supported by reasons based consequentialism, relying as it does

19 Ibid. p. 228.

20 Ibid. p. 230. 
on measures of the objective strength of reasons particular people have. There are various other ways such a rejection of small chances of life or small amounts of remaining life-span, might be supported. Such a plateau might, for example, be supported by some overarching theory of distributive justice. Such a theory might of course run into equally counter-intuitive conclusions in other areas, as I have suggested is the case with Savulescu's version of reasons based consequentialism.

For these reasons I believe the paradoxical consequences of according equal concern and respect to claims to small chances of life, or small periods of continued existence, is more apparent than real. A reasons based consequentialism which is not burdened by the absurdities of the principle of temporal neutrality and is sensitive to the strength of reasons that particular individuals have to take their own chances on life, would probably be fully compatible with the position that I have defended. We must remember, however, that the crucial issue is that of distributive justice, of how public resources may be allocated to do justice to the equal claims of individual citizens. What matters therefore, is what a distributor of the public resources available for healthcare should do.

There is, I believe, no way to formalise at the level of public policy the information necessary to be fully sensitive to, and respectful of, individual reasons and circumstances. A distributor of public resources cannot (and perhaps should not) know or enquire into the detailed reasons why even a small chance of life or a short period of remission is wanted and needed. Such a distributor should be 'blind' to these individual differences, for to evaluate them violates the equality principle. This is why a distributor of public resources must afford equal opportunities for healthcare and not formalise principles that may accord different value to the lives of equals.

The Institute of Medicine, Law and Bioethics

The University of Manchester 